\title{
A patient with Simpson-Golabi-Behmel syndrome and hepatocellular carcinoma
}

\author{
Pablo Lapunzina, Isabel Badia, Cristina Galoppo, Elena De Matteo, Pedro Silberman, \\ Ana Tello, Jorge Grichener, Rhiannon Hughes-Benzie
}

\section{Department of \\ Paediatrics, Hospital de Niños de Buenos Aires, University of Buenos Aires, Darwin 1154 D1A, 1414 Buenos Aires, Argentina \\ P Lapunzina \\ J Grichener \\ Department of Hepatology, Hospital de Niños de Buenos Aires, University of Buenos Aires, Argentina \\ I Badia \\ C Galoppo}

Department of Pathology, Hospital de Niños de Buenos Aires, University of Buenos Aires, Argentina E De Matteo

Department of Paediatrics, Centro Dr "Leonidas Lucero", Bahía Blanca, Argentina

P Silberman

Department of Genetics, Hospital de Niños de Buenos Aires, University of Buenos Aires, Argentina

A Tello

Molecular Genetics Laboratory, Children's Hospital of Eastern Ontario, Canada R Hughes-Benzie

Correspondence to: Dr Lapunzina.

Received 21 May 1997 Revised version accepted for publication 29 August 1997

\section{Abstract}

Simpson-Golabi-Behmel

syndrome (SGBS) is an $\mathrm{X}$ linked disorder characterised by pre- and postnatal overgrowth, coarse facial features, and visceral and skeletal abnormalities. Like other overgrowth syndromes, in the SGBS there is an increased risk for developing neoplasia, mainly embryonic, such as Wilms tumour. We report a 3 year old male patient with SGBS and hepatocellular carcinoma, a previously undescribed tumour associated with the syndrome. ( 7 Med Genet 1998;35:153-156)

Keywords: GPC3 gene; hepatocellular carcinoma; overgrowth syndrome; Simpson-Golabi-Behmel syndrome

Simpson-Golabi-Behmel syndrome (SGBS, MIM 312870) is an $X$ linked condition characterised by pre- and postnatal overgrowth and by a variety of congenital defects such as multiple midline malformations, cardiac and vertebral anomalies, coarse face, macroglossia, organomegaly, and developmental delay.

In this condition there is a higher than expected incidence of embryonic neoplasia, including Wilms tumour, atypical embryoma, and neuroblastoma. Affected males may also be at risk for developing other embryonal tumours including hepatoblastoma and rhabdomyosarcoma.

The primary defect has recently been assigned to a gene mapping on Xq26 which encodes a putative extracellular proteoglycan, glypican-3 (GPC3). Such a proteoglycan is inferred to play an important role in growth control in mesodermal tissues ${ }^{2}$ and in tumour predisposition. ${ }^{3}$ Four new GPC3 mutations have recently been identified in nine additional patients. ${ }^{4}$

We report on a 3 year old male patient with clinical findings of SGBS and hepatocellular carcinoma. As far as we know this is the first patient with SGBS with a primary epithelial neoplasm of the liver.

\section{Case report}

The child was born prematurely ( 36 weeks) as the second child of young, nonconsanguineous parents. The pregnancy was complicated by polyhydramnios and resulted in delivery by caesarean section. His mother had a coarse face with a broad nasal bridge, epicanthic folds, and abnormal dentition including dental malocclusion and enamel defects. The father was healthy and had no abnormal features. The patient's 7 year old sis- ter was not examined but was reported to be normal with "mild speech difficulties". At birth his weight was $4100 \mathrm{~g}$ (97th centile), length was $54 \mathrm{~cm}$ (97th centile), and head circumference (OFC) was $34.5 \mathrm{~cm}$ (60th centile). $\mathrm{He}$ was macrosomic with a left sided cleft lip and palate, macroglossia, anal stenosis, and a tender, subcutaneous tumour on the forehead. At the age of 1 month, both rain CT scan and MRI disclosed normal ventricles with no enlarged cysternae and a dysplastic corpus callosum with a lipoma in the splenium. During the following months he grew above the 97th centile in both weight and height. Cleft lip and palate had been repaired at 8 months (fig 1). Results of BAEP audiometry were indicative of moderate hearing loss.

The proband came to our hospital for evaluation of a severely enlarged liver. When examined by us aged 3 years 2 months his weight was $19.7 \mathrm{~kg}$ ( $>97$ th centile), height $104.6 \mathrm{~cm}$ ( $>95$ th centile), OFC was $50.5 \mathrm{~cm}$ (60th centile), and cephalic index was normal. Internipple distance was $14.5 \mathrm{~cm}$ (>95th centile). He had a surgically repaired cleft lip and palate, upturned, bulbous nose, wide nasal bridge, mild hypertelorism, macrostomia, macroglos-

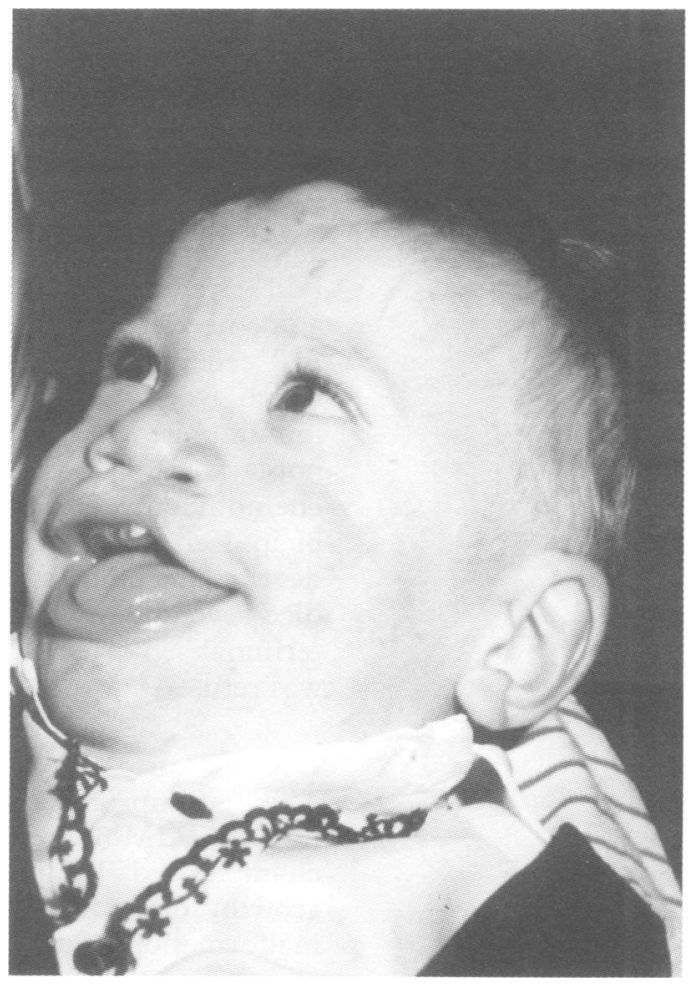

Figure 1 The patient at about 8 months. Note the abnormal, coarse face, macroglossia, and lipoma on the forehead. (Courtesy of the late Dr H Marino Ochoa; all photographs reproduced with permission.) 


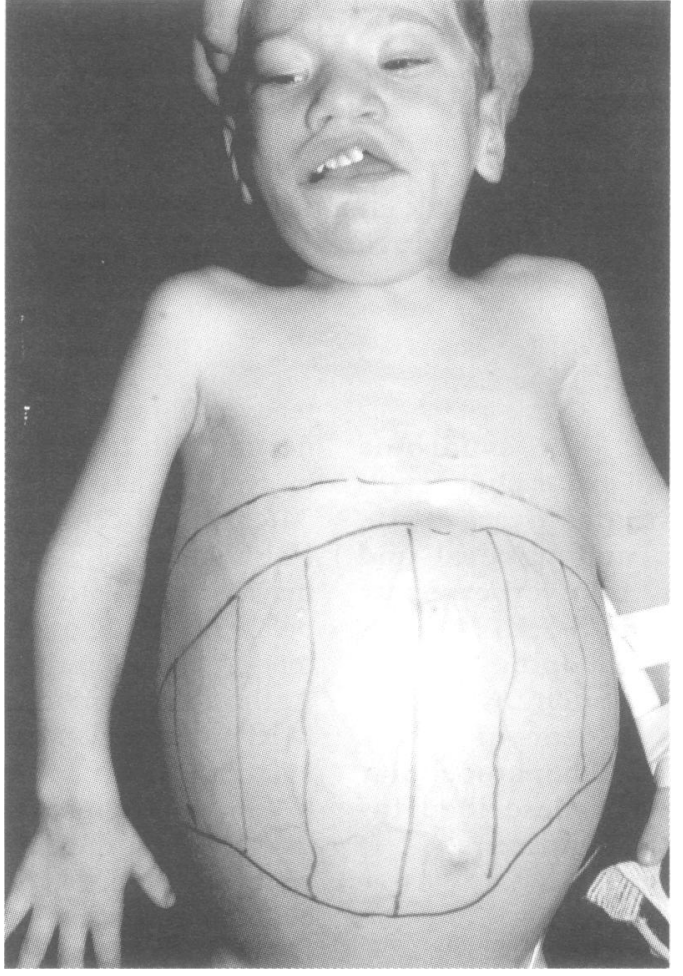

Figure 2 The proband aged 3 years 2 months. Note the severely enlarged liver.

sia, midline grooved tongue, a lipoma on his forehead, one occipital naevus flammeus, three very small left accessory nipples, pectus excavatum, atrial septal defect, and hepatomegaly, the liver occupying almost all the abdominal cavity (fig 2). His hands were broad and short, with shortening of the distal phalanges (fig 3). Bone age was 3 years. Speech and neurological development were mildly delayed, as was motor development because he had not been able to pull to stand or walk.

Ultrasound examination of the liver and abdominal CT scan both disclosed multiple cystic lesions in the hepatic parenchyma (fig 4). Routine laboratory tests were unremarkable and thyroid hormones were normal. Serum alphafetoprotein was extremely high at 17500 IU/1 (reference value 0-10 IU/1). He underwent a fine needle liver biopsy which showed abnormal cells with a pseudoglandular appearance which were positive for alphafetoprotein on immunohistochemistry. Hepatocellular carcinoma was diagnosed and the patient began chemotherapy with carboplatin plus doxorubicin. Ten days later he became neutropenic, developed a blood stained pleural effusion, and died several days later as a result of intractable terminal septicaemia. Permission for necropsy was refused.

\section{Discussion}

The Simpson-Golabi-Behmel syndrome (SGBS, MIM 312870) is an X linked disorder characterised by pre- and postnatal overgrowth, organomegaly, cardiac and skeletal malformations, and other abnormalities. In addition to the families identified in the three original papers by Simpson et $a l^{5}$ Golabi and Rosen, ${ }^{6}$ and Behmel et al, ${ }^{7}$ there have been several additional publications identifying affected

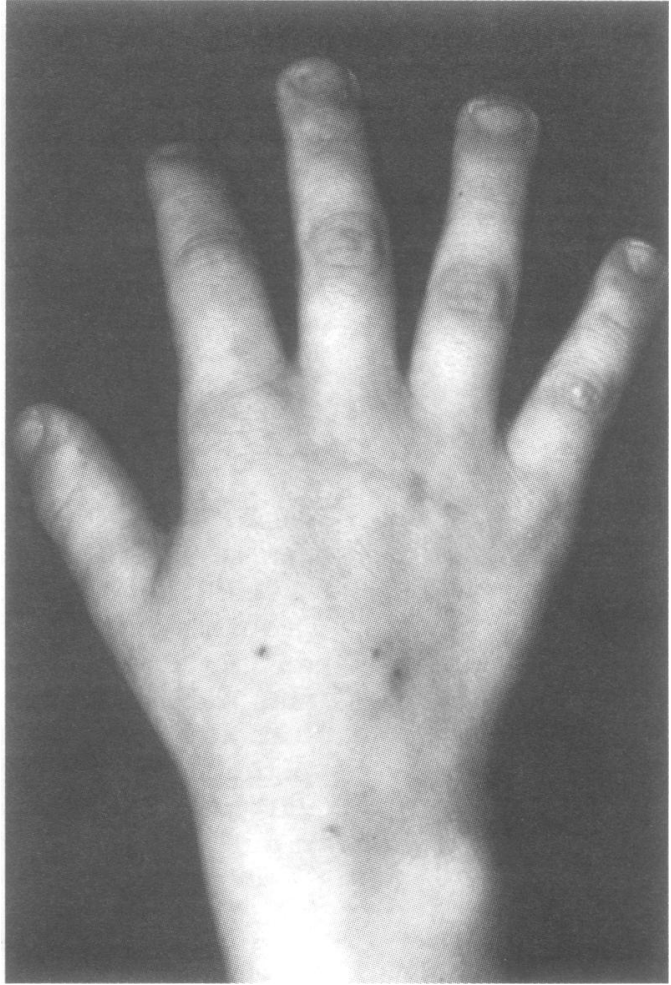

Figure 3 Broad, short hands with shortening of distal phalanges.

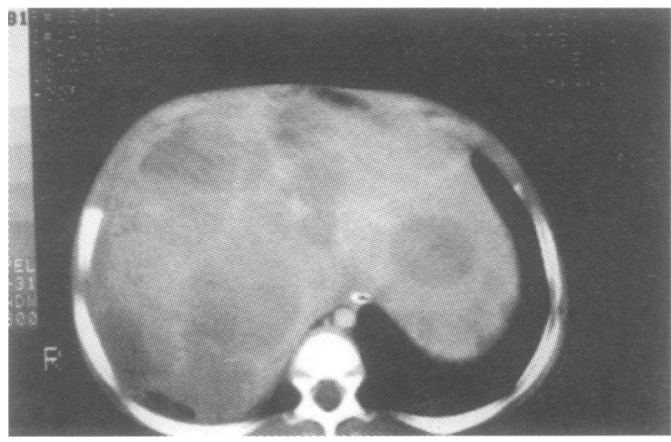

Figure 4 Abdominal CT scan showing multiple cystic lesions in the liver.

patients (reviewed by Garganta and Bodurtha $\left.^{8}\right)$. Thus, more than 30 patients have been reported so far, ${ }^{9}$ in more than 18 families. ${ }^{10}$ There is a wide clinical spectrum in reported cases of SBGS ranging from the more common mild form associated with long term survival to an early lethal form with multiple congenital anomalies and severe mental retardation..$^{81011}$

The present patient had classical manifestations of SGBS, such as cleft lip and palate, upturned nose, wide nasal bridge, hypertelorism, macroglossia, midline grooved tongue, supernumerary nipples, atrial septal defect, and organomegaly. In addition, he had a severely enlarged liver owing to a hepatocellular carcinoma. Though some tumours have already been reported in SGBS, particularly atypical embryoma, neuroblastoma, and Wilms tumour (table 1), ${ }^{1412}$ as far as we know this is the first case of SGBS and hepatocarcinoma.

Liver tumours have been described in association with some overgrowth syndromes, such as the hemihypertrophy syndrome and Sotos syndrome (hepatocellular carcinoma) ${ }^{13}{ }^{14}$ 
Table 1 Tumours reported in patients with the Simpson-Golabi-Behmel syndrome

\begin{tabular}{llllll}
\hline $\begin{array}{l}\text { Family and ID } \\
\text { No }\end{array}$ & Age at diagnosis & Sex & $\begin{array}{l}\text { GPC3 gene exon(s) } \\
\text { deleted }\end{array}$ & Type of tumour & Reference \\
\hline A II.5 & $19 \mathrm{mth}$ & $\mathrm{M}$ & 2 & Adrenal neuroblastoma & 2,4 \\
A III.2 & $19 \mathrm{mth}$ & $\mathrm{M}$ & 2 & Wilms tumour & 2,4 \\
G II.3 & - 3 y & M & 1 & Wilms tumour & 4 \\
SGB-2 & $?$ & M & NDD & Wilms tumour & 25 \\
SGB-4 & $7 \mathrm{y}$ & M & 1 and 2 & Wilms tumour & 25 \\
$?$ & Neonate & $\mathbf{M}^{\star}$ & NP & Benign gonadoblastoma & $26 \dagger$ \\
UC & 3 y 2 mth & M & NP & Hepatocellular carcinoma & Present case \\
\hline
\end{tabular}

NP: not performed.

NDD: no deletion detected.

?Unknown.

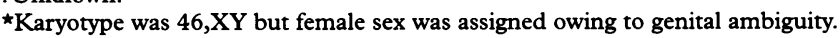

tAt the workshop, the diagnosis of Simpson-Golabi-Behmel syndrome was established and Beckwith-Wiedemann syndrome rejected.

and Beckwith-Wiedemann syndrome (hepatoblastoma). ${ }^{15-17}$ In overgrowth syndromes, serum alphafetoprotein is considered to be an important marker for embryonal cell tumours. ${ }^{18}$ Therefore, the association of hepatocellular carcinoma and SGBS, though previously undescribed, might have been expected. In patients with somatic overgrowth, HughesBenzie et al (unpublished data) recommended that embryonal tumours might be routinely screened by serum alphafetoprotein and betahCG measurements plus abdominal ultrasound every four months up to 5 years of age, every six months between 5 and 8 years, and yearly in children older than 8 years. The present patient had not been on a tumour screening programme because he had not been diagnosed as having SGBS until he was referred to our hospital.

Lipomas of the scalp or corpus callosum have not been previously reported in SGBS patients. The significance of these findings is not clear but could be related to the tumour predisposition observed in this type of overgrowth syndrome. Lipomas have been observed in other disorders with overgrowth, such as the Proteus syndrome and the BannayanRuvalcaba-Myhre syndrome.

The phenotype of the proband's mother was also remarkable. She had a coarse face with a broad nasal bridge, epicanthic folds, and abnormal dentition, including dental malocclusion and enamel defects. Manifestations observed in at least one mother in the report of Golabi and Rosen ${ }^{6}$ probably represent a lyonisation effect and should be looked for in all female relatives of SGBS children. Extreme lyonisation distortion during development can result in a heterozygous female with a phenotype as severe as seen in hemizygotes. This was reported in two females with typical features of SGBS and X;autosome translocations. ${ }^{24} 19$

Linkage analysis performed in several families mapped the SGBS gene to the long arm of the $\mathrm{X}$ chromosome, close to the HPRT locus. ${ }^{12} 20$ Pilia et $a l^{2}$ have provided strong evidence for GPC3, a member of the glypican related integral membrane proteoglycan family, as a candidate for the SGBS gene. The gene GPC3, which encodes the putative extracellular proteoglycan GPC3, is inferred to play an important role in growth control in embryonal mesodermal tissues. It appears that intact GPC3 would form a complex with insulin-like growth factor 2 (IGF2) sequestering the latter, or could facilitate downregulation and turnover of IGF2 through a further interaction with IGF2 receptor (also known as mannose-6phosphate receptor, M6P/IGF2R). SGBS could thus result from loss of function mutations that reduce GPC3 binding and thereby increase the active level of IGF2. ${ }^{2}$ From the phenotype of dysplasia-gigantism in SGBS, they speculated that GPC3 would be involved in the suppression/modulation of growth in the predominantly mesodermal tissues and organs that show high levels of GPC3 and would tend to overgrow in its absence. $^{2}$ Moreover, the similarity in the mutant phenotypes of SGBS patients and Igf2r transgenic mice suggests that glypican- 3 and IGF2 receptor function sequentially or as coreceptors for IGF2. In this way, a deficiency of either could result in increased or abnormal IGF2 activity. ${ }^{3}$ Another possibility is that GPC3 normally facilitates programmed cell death (apoptosis), balancing the role of IGF2 in promoting cell growth. Thus, GPC3 deficiency might lead to overgrowth and tumour predisposition. ${ }^{3}$ Recently, using Southern blot analysis and PCR amplification of intraexonic sequences, Hughes-Benzie et al ${ }^{4}$ identified four new GPC3 mutations. Deletions were identified throughout the length of the GPC3 transcript with no evidence of mutation hot spots. On the other hand, De Souza et $a l^{1}$ have recently shown that $70 \%$ of human hepatocellular tumours have loss of heterozygosity at the M6P/IGF2R locus and they have identified point mutations in the remaining allele of $25 \%$ of the human hepatocellular carcinomas with loss of heterozygosity, providing evidence that the $\mathrm{M} 6 \mathrm{P} / \mathrm{IGF} 2 \mathrm{R}$ functions as a tumour suppressor in human liver carcinogenesis. ${ }^{22}$ Thus, the interactions between GPC3, M6P/IGF2R, and IGF2 seem to be essential in the pathophysiology of late embryonic development, somatic growth, and carcinogenesis. The observation of SGBS and hepatocellular carcinoma in the patient reported here further supports the interaction of these proteins.

Though there is considerable clinical overlap between SGBS and Beckwith-Wiedemann syndrome (macrosomia, cleft palate, visceromegaly, macroglossia, herniae, neonatal hypoglycaemia, and risk of tumours), which have led to confusion, it is very important to differentiate them because genetic counselling varies, the former being an $\mathrm{X}$ linked recessive syndrome and the latter autosomal dominant with 
imprinting. ${ }^{23} 24$ The tumour risk for BWS is $5-10 \%{ }^{3}$ and that for SGBS is as yet undefined, but could be estimated as $10-15 \%$. This tumour development in SGBS has been observed in patients with deletions of the $5^{\prime}$ end of the GPC3 gene (table 1). ${ }^{2425}$

Accurate diagnosis of somatic overgrowth disorders and molecular analysis of DNA samples for the GPC3 gene might be helpful for prenatal diagnosis in SBGS families and for patients with somatic overgrowth and tumours.

We are deeply indebted to Dr Horacio M Ochoa who followed up the child until he was referred to us.

1 Hughes-Benzie RM, Hunter AGW, Allanson JE, MacKenzie AE. Simpson-Golabi-Behmel syndrome associated with renal dysplasia and embryonal tumour: localization of the gene to Xqcen-q21. Am f Med Genet 1992;43:428-35.

2 Pilia G, Hughes-Benzie RM, MacKenzie A, et al. Mutations in GPC3, a glypican gene, cause the Simpson-Golabiin GPC3, a glypican gene, cause the Simpson-Golabi-

3 Weksberg R, Squire JA, Templeton DM. Glypicans: a growing trend. Nat Genet 1996;12:225-7.

4 Hughes-Benzie RM, Pilia G, et al. Simpson-Golabi Behme syndrome: genotype/phenotype analysis of 18 males from 7 unrelated families. Am $\mathcal{F}$ Med Genet 1996;66:227-34.

5 Simpson JL, Landey S, New M, German J. A previously unrecognized X-linked syndrome of dysmorphia. Birth Defects 1975;XI:18-24.

6 Golabi M, Rosen L. A new X-linked mental retardationovergrowth syndrome. Am 7 Med Genet 1984;17:345-58.

7 Behmel A, Plochl E, Rosenkranz W. A new X-linked dysplasia gigantism syndrome: identical with the Simpson dysplasia syndrome? Hum Genet 1984;67:409-13.

8 Garganta CL, Bodurtha NN. Report of another family with Simpson-Golabi-Behmel syndrome and a review of the literature. Am ₹ Med Genet 1992;44:129-35.

9 Taybi H, Lachman RS. Radiology of syndromes, metabolic disorders, and skeletal dysplasias. 4th ed. Saint Louis: Mosby, 1996:454-5.

10 Terespolsky D, Farrell SA, Siegel-Bartelt J, Weksberg R. Infantile lethal variant of Simpson-Golabi-Behmel syndrome associated with hydrops fetalis. Am $\mathcal{F}$ Med Genet 1995;59:329-33.

11 Opitz JM, Hermann J, Gilbert EF, Matalon R. SimpsonGolabi-Behmel syndrome: follow-up of the Michigan family. Am F Med Genet 1988;30:301-8.
12 Xuan JY, Besner A, Ireland $M$, Hughes-Benzie RM, MacKenzie AE. Mapping of Simpson-Golabi-Behmel syndrome to Xq25-q27. Hum Mol Genet 1994;3:133-7.

13 McGoldrick JP, Boston VE, Glasgow JFT. Hepatocellular carcinoma associated with congenital macronodular cirrhosis in a neonate. $\mathcal{F}$ Pediatr Surg 1986;21:177-9.

14 Ishak KG, Glunz PR. Hepatoblastoma and hepatocarcinoma in infancy and childhood: report of 47 cases. Cancer 1967;20:396-422.

15 Wilfong AA, Parke JT, McCrary JA. Opsoclonus-myoclonus with Beckwith-Wiedemann syndrome and hepatoblastoma. Pediatr Neurol 1992;8:77-9.

16 Martelli C, Blandamura S, Massaro S, Zulian M, Altavill G, Piazza M. A case study of Beckwith-Wiedemann syndrome associated with hepatoblastoma. Clin Exp Obstet Gynecol 1993;20:82-7.

17 Jones KL. The etiology and diagnosis of overgrowth syndromes. Growth Genet Horm 1994;10:6-10.

18 Wiedemann HR. Tumors and hemihypertrophy associated with Wiedemann-Beckwith syndrome. Eur $f$ Pediatr 1983;141:129.

19 Punnett HH. Simpson-Golabi-Bemhel syndrome (SGBS) in a female with an $\mathrm{X}$-autosome translocation. $\mathrm{Am} \mathrm{f} \mathrm{Med}$ Genet 1994;50:391-3.

20 Orth U, Gurrieri F, Behmel A, Genuardi M, Cremer M, Ga A. Gene for Simpson-Golabi-Behmel syndrome is linked to HPRT in Xq26 in two European families. Am 7 Med Genet 1994;50:388-90.

21 De Souza AT, Hankins GR, Washington MK, Fine RI Orton TC, Jirtle RL. Frequent loss of heterozygosity on $6 \mathrm{q}$ ar the mannose 6-phosphate/insulin-like growth factor II at the mannose 6-phosphate/insulin-like growth factor II receptor locus in

22 De Souza AT, Hankins GR, Washington MK, Orton TC Jirtle RL. M6P/IGF2R gene is mutated in human hepatocellular carcinomas with loss of heterozygosity. Nat Genet 1995;11:447-9.

23 Hughes-Benzie R, Allanson J, Hunter A, Cole T. The importance of differentiating Simpson-Golabi-Behmel and importance of differentiating Simpson-Golabi-Behmel and Beck.

24 Hughes-Benzie RM, Tolmie JL, McNay M, Patrick A Simpson-Golabi-Behmel syndrome: disproportionate feta overgrowth and elevated maternal serum alphafetoprotein. Prenat Diagn 1994;14:313-18.

25 Lindsay S, Ireland M, O'Brien O, et al. Large scale deletions in the GPC3 gene may account for a minority of cases of Simpson-Golabi-Behmel syndrome. 7 Med Genet 1997;34: 480-3.

26 Harrod MJ. Familial Beckwith-Wiedemann syndrome with pseudohermaphroditism in a $46, \mathrm{XY}$ female. Proc Greenwood Genetic Center 1992;12:93A 